Article

\title{
Efficient and Selective Adsorption of Gold Ions from Wastewater with Polyaniline Modified by Trimethyl Phosphate: Adsorption Mechanism and Application
}

\author{
Chen Wang ${ }^{1,2,3}$, Jiling Zhao ${ }^{1,2,3}$, Shixing Wang ${ }^{1,2,3, *}$, Libo Zhang ${ }^{1,2,3, * \mathbb{D}}$ and Bing Zhang ${ }^{1,2,3}$ \\ 1 National Local Joint Laboratory of Engineering Application of Microwave Energy and Equipment \\ Technology, Kunming 650093, China; wc932608335@163.com (C.W.); 15687884157@163.com (J.Z.); \\ 15198750002@163.com (B.Z.) \\ 2 State Key Laboratory of Complex Nonferrous Metal Resources Clean Utilization (Kunming University of \\ Science and Technology), Kunming 650093, China \\ 3 Faculty of Metallurgical and Energy Engineering, Kunming University of Science and Technology, \\ Kunming 650093, China \\ * Correspondence: wsxkm@kmust.edu.cn (S.W.); zhanglibopaper@126.com (L.Z.); \\ Tel.: +86-135-2920-4964 (S.W.); +86-871-6513-8997 (L.Z.)
}

Received: 28 February 2019; Accepted: 7 April 2019; Published: 9 April 2019

\begin{abstract}
The selective recovery of gold from wastewater is necessary because it is widely used in various fields. In this study, a new polymeric adsorbent (TP-AFC) was prepared by modifying polyaniline with trimethyl phosphate for the selective recovery of gold from wastewater. Bath experiments were carried out to explore the adsorption capacity and mechanism. The optimum $\mathrm{pH}$ of adsorption is 4 . The adsorption equilibrium is reached at $840 \mathrm{~min}$. The maximum adsorption capacity is $881 \mathrm{mg} / \mathrm{g}$ and the adsorption was a spontaneous endothermic process. The adsorption process fitted well with pseudo second-order kinetic and the Langmuir-models. The single-layer chemisorption governed the adsorption process. In addition, the application in wastewater indicated that the interfering ions had no effect on the adsorption of gold ions. TP-AFC has good selectivity. The interaction mechanism was mainly ion exchange and complexation. In general, TP-AFC was successfully prepared and has an excellent future in practical application.
\end{abstract}

Keywords: $\mathrm{Au}(\mathrm{III})$, polymer; wastewater; adsorption; mechanism

\section{Introduction}

In modern industry, precious metals are widely used in various fields [1]. As one of the most important precious metals, gold was wildly used in electronics catalysis, medicine and the jewelry industry [2-5]. As far as capacity is concerned, the supply of gold is far from meeting the growing demand. Gold ions can also trigger bioaccumulation problems when they were emitted into the aqueous solution. Therefore, it is very important to recover gold from wastewater.

Recently, various approaches have been developed to recover gold from wastewater, including electrolysis, solvent extraction, membrane filtration and adsorption [6-10]. In the above methods, adsorption is a valid method with the advantage of low cost, high efficiency and easy synthesis [11]. A variety of adsorbents have been used to remove metal ions from aqueous solutions, including resin, zeolites, nanomaterials and polymer [12-15]. Among them, functional polymers have been extensively applied to the adsorption field, such as polyaniline $[16,17]$. Usually, the polymers were typically used as inactive carrier materials to increase the particle size and effective specific surface area [18-20]. However, the total volume and weight of adsorbents are greatly increased due to adding the carrier 
materials. These factors decrease the adsorption capacity. Hence, on the premise of ensuring adsorption capacity and selectivity, the choice of carrier material is also very important for the polymer adsorbent.

In general, for rare and expensive metal ion adsorbents, phosphorus-containing functional groups are used to embellish them, including $\mathrm{P}-\mathrm{O}, \mathrm{P}=\mathrm{O}, \mathrm{P}-\mathrm{C}$ and etc. As a cheap industrial product, trimethyl phosphate is rich in phosphorus functional groups $(\mathrm{P}-\mathrm{O}, \mathrm{P}=\mathrm{O})$ [21]. However, there are few reports on the modification of polymers with trimethyl phosphate.

In this research, polyaniline-based adsorbent (TP-AFC) was successfully synthesized by grafting trimethyl phosphate. The adsorbent was characterized by Fourier transform infrared spectroscopy (FT-IR), X-ray photoelectron spectroscopy (XPS), Scanning Electron Microscope (SEM), and Energy Dispersive Spectrometer (EDS). In batch adsorption experiments, several factors were investigated e.g. $\mathrm{pH}$, initial concentration, reaction time, and temperature. The practical application in wastewater with coexisting ions was examined. The adsorption mechanism was investigated by batch experiments, adsorption isothermal, and kinetic models.

\section{Materials and Methods}

\subsection{Materials}

Aniline, isopropanol, formaldehyde, acetic acid, and trimethyl phosphate were purchased from Aladdin Chemical Co., Ltd. (Shanghai, China). The reagents were analytical grade and were not further processed. Gold ion standard solution and mixed ion standard solution were provided by Tianjin Zhiyuan Co., Ltd. (Tianjin, China). Hydrochloric acid and sodium hydroxide were used to adjust the $\mathrm{pH}$ of the solution.

\subsection{Synthesis of Adsorbent}

TP-AFC is synthesized according to Scheme 1. Polyaniline was prepared according to the literature [22]. Firstly, $25 \mathrm{~mL}$ isopropanol, $0.03 \mathrm{~mol}$ of aniline and $3 \mathrm{~mL}$ concentrated hydrochloric acid $(12 \mathrm{~mol} / \mathrm{L})$ were added to beaker $\mathrm{A}$ and kept on an ice bath. $5 \mathrm{~mL}$ formaldehyde (37\%) and $25 \mathrm{~mL}$ isopropanol were sequentially added to beaker B. Finally, the solution in beaker B was added to the previously cooled beaker A and stirred vigorously to obtain a homogeneous solution. After reacting at 273-278 K for $25 \mathrm{~min}$, it was slowly warmed to room temperature and polyaniline was obtained.<smiles>CC(C)C(O)C(C)C(C)(C)c1cccc(C(C)(C)CCl)c1[O-]</smiles>

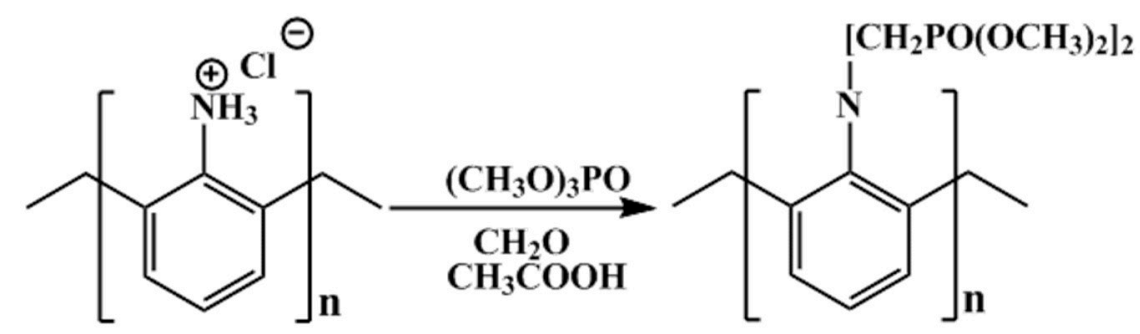

Scheme 1. The synthesis of TP-AFC. 
3 g polyaniline, $0.06 \mathrm{~mol}$ trimethyl phosphate, $2 \mathrm{~mL}$ acetic acid and $10 \mathrm{~mL}$ formaldehyde were sequentially added to a three-necked flask and stirred at $358 \mathrm{~K}$ for $3 \mathrm{~h}$. The final product was obtained after centrifugation. This product was named TP-AFC.

\subsection{Batch Experiments}

Batch adsorption experiments were carried out to study the influence of $\mathrm{pH}$, initial concentration, and reaction time. $10 \mathrm{mg}$ TP-AFC was firstly added to a $20 \mathrm{~mL}$ solution. The solution was oscillated at $298 \mathrm{~K}$ and $250 \mathrm{rpm}$. In addition, the effect of temperature on the absorption capacity was studied at $298 \mathrm{~K}, 308 \mathrm{~K}$ and $318 \mathrm{~K}$. In order to investigate the reusability of the adsorbent, a repetitive experiment was conducted. A thiourea hydrochloride desorbent was used. In order to study the practical application, $10 \mathrm{mg}$ TP-AFC was added to $20 \mathrm{~mL}$ laboratory wastewater and oscillated at $298 \mathrm{~K}$ and $250 \mathrm{rpm}$. In all batch experiments, the supernatant was collected after centrifugation at $9000 \mathrm{rpm}$ for 10 minutes and the remaining ion concentration was measured using inductively coupled plasma optical emission spectrometer. The removal rate of gold ions $(\mathrm{R})$ and the equilibrium adsorption capacity $\left(\mathrm{q}_{\mathrm{x}}\right)$ were calculated by the following equation [23].

$$
\begin{gathered}
R=\frac{\left(C_{y}-C_{r}\right)}{C_{y}} \times 100 \% \\
q_{x}=\frac{\left(C_{y}-C_{r}\right)}{m} V
\end{gathered}
$$

where $C_{y}$ and $C_{r}$ are the initial concentration and residual concentration of gold ions, respectively. $V$ $(\mathrm{mL})$ and $\mathrm{m}(\mathrm{mg})$ are the volume of the gold ion solution and the weight of TP-AFC, respectively.

\subsection{Characterization}

Fourier transform infrared spectroscopy (FT-IR) was measured by Nicolet iS50 FT-IR spectrophotometer (Thermo Nicolet, Waltham, MA, USA) between $400 \mathrm{~cm}^{-1}$ and $4000 \mathrm{~cm}^{-1}$ with a resolution of $4 \mathrm{~cm}^{-1}$. Scanning-Electron-Microscope (SEM, Phenom pro X, Netherlands.) was used to characterize the size and morphology of polyaniline and TP-AFC. The surface state of the adsorbent during adsorption was characterized by XPS (Thermo Scientific Co., $1486.6 \mathrm{eV}$ monochromated Al K-alpha radiation source, Chanhassen, MN, USA). The concentration of metal ions was detected by inductively coupled plasma optical emission spectrometer (ICP-OES, LEEMAN prodigy 7, Hudson, Wenthworth Drive, NH, USA).

\section{Results and Discussion}

\subsection{Characterization of TP-AFC}

The FT-IR spectra of polyaniline and TP-AFC are shown in Figure 1. The peaks at $820 \mathrm{~cm}^{-1}$, $1667 \mathrm{~cm}^{-1}, 1596 \mathrm{~cm}^{-1}$ and $3414 \mathrm{~cm}^{-1}$ represented the $\mathrm{CH}, \mathrm{C}-\mathrm{N}, \mathrm{N}-\mathrm{H}$ and O-H bonds, respectively. TP-AFC showed two new peaks compared to polyaniline at $943 \mathrm{~cm}^{-1}$ and $1051 \mathrm{~cm}^{-1}$. They represented the P-O and $\mathrm{P}=\mathrm{O}$ bonds, respectively. This indicated that the trimethyl phosphate was successfully grafted.

The SEM images of polyaniline and TP-AFC are shown in Figure 2. It can be found that the morphology of the adsorbent does not substantially change after being grafted. This showed that the adsorbent had a stable structure. The modification rate of the amine can be calculated by the data obtained by SEM-EDS and the structural formula of polymer. One nitrogen atom is grafted with two phosphorus atoms. The calculated modification rate of amine is $20.6 \%$. 


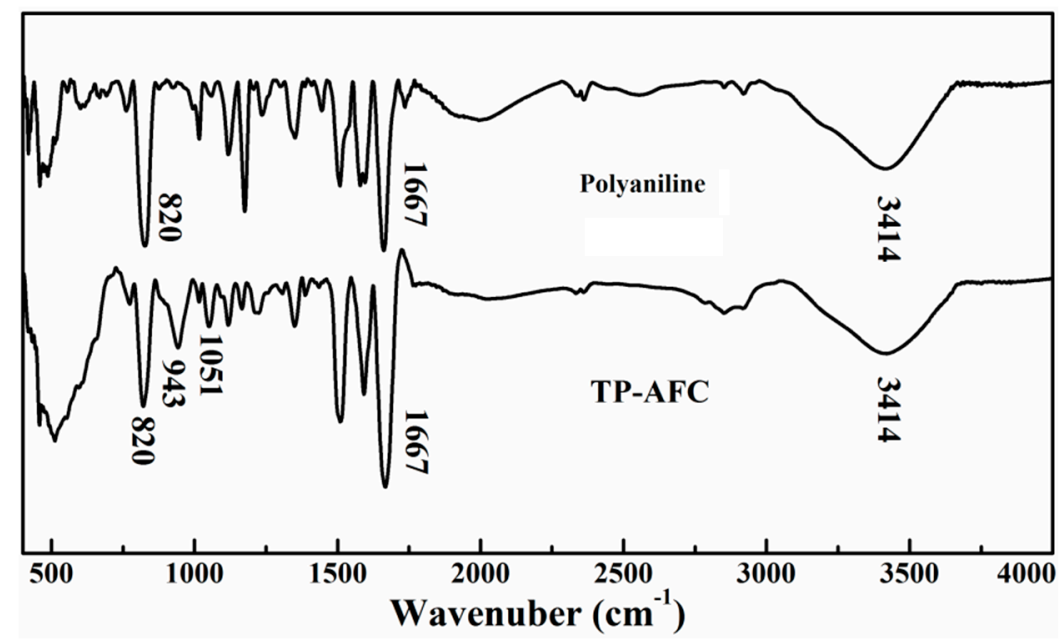

Figure 1. FT-IR spectra of polyaniline and TP-AFC.
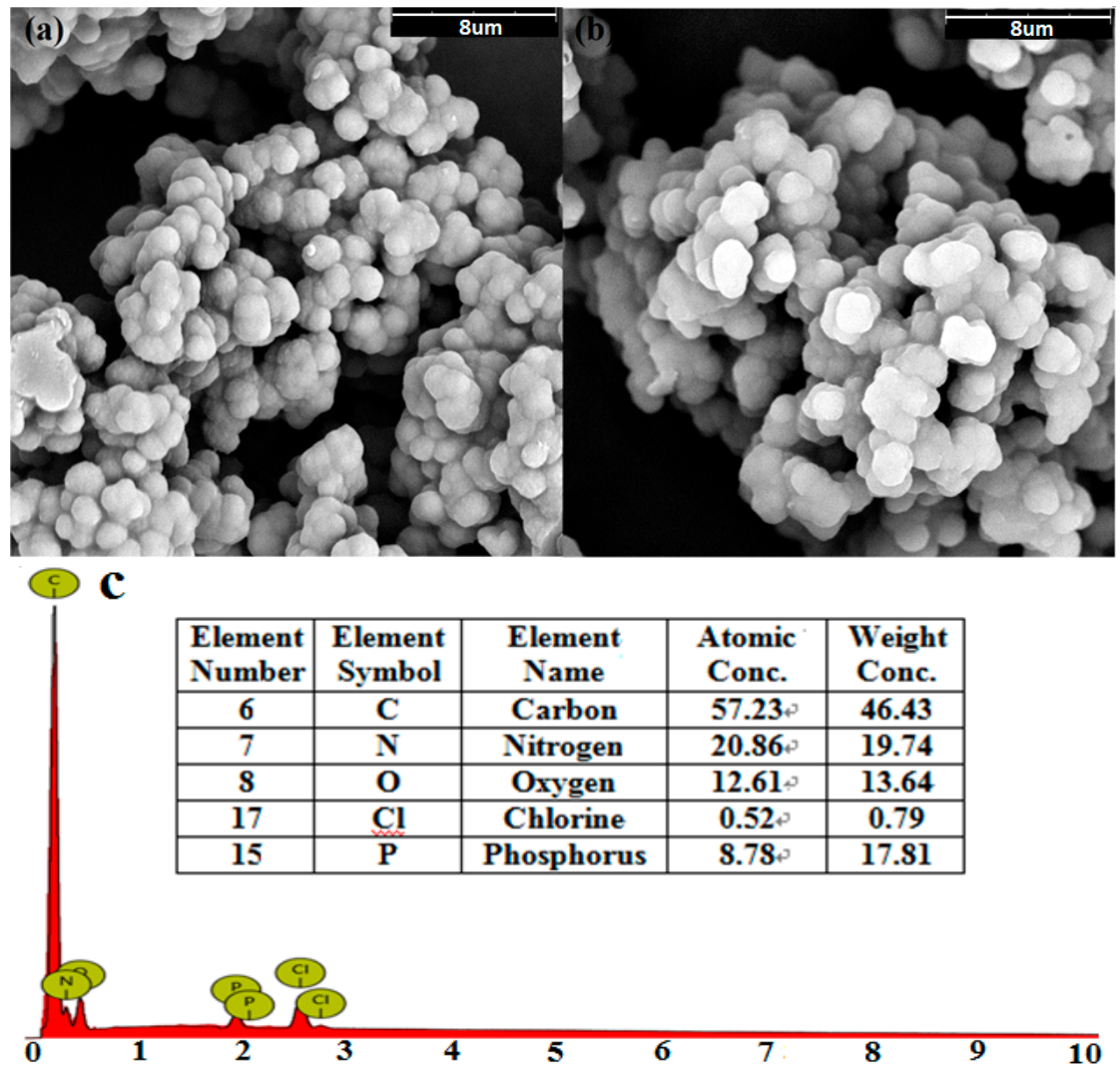

Figure 2. SEM images of polyaniline (a) and TP-AFC (b), EDS of TP-AFC (c).

\subsection{Effect of $p H$}

Solution $\mathrm{pH}$ has an important influence on the removal ability of metal ions. The effect of $\mathrm{pH}$ from 2 to 11 was studied when the concentration of gold ion was $200 \mathrm{mg} / \mathrm{L}$. Figure 3a showed that the adsorption capacity varies greatly with the change in $\mathrm{pH}$. Obviously, TP-AFC shows the excellent adsorption ability in the $\mathrm{pH}$ range of 2 to 6 . The maximum removal rate of gold ions by TP-AFC was occurred at $\mathrm{pH} 4$. In contrast, the good removal rate of gold ions by polyaniline was occurred in the $\mathrm{pH}$ range of 2 to 4 . When the $\mathrm{pH}$ is too high, the hydroxide $\left(\mathrm{OH}^{-}\right)$in the solution competes with the 
adsorbent, resulting in a sharp drop in the adsorbing capacity. As the $\mathrm{pH}$ of the solution changes, gold ions mainly exist in the following forms:

$$
\begin{gathered}
\mathrm{Au}(\mathrm{OH})_{4}+\mathrm{H}^{+}+\mathrm{Cl}^{-} \rightleftharpoons \mathrm{AuCl}(\mathrm{OH})_{3}^{-}+\mathrm{H}_{2} \mathrm{O} \\
\mathrm{AuCl}(\mathrm{OH})_{3}^{-}+\mathrm{H}^{+}+\mathrm{Cl}^{-} \rightleftharpoons \mathrm{AuCl}_{2}(\mathrm{OH})_{2}^{-}+\mathrm{H}_{2} \mathrm{O} \\
\mathrm{AuCl}_{2}(\mathrm{OH})_{2}^{-}+\mathrm{H}^{+}+\mathrm{Cl}^{-} \rightleftharpoons \mathrm{AuCl}_{3}(\mathrm{OH})^{-}+\mathrm{H}_{2} \mathrm{O} \\
\mathrm{AuCl}_{3}(\mathrm{OH})^{-}+\mathrm{H}^{+}+\mathrm{Cl}^{-} \rightleftharpoons \mathrm{AuCl}_{4}^{-}+\mathrm{H}_{2} \mathrm{O}
\end{gathered}
$$
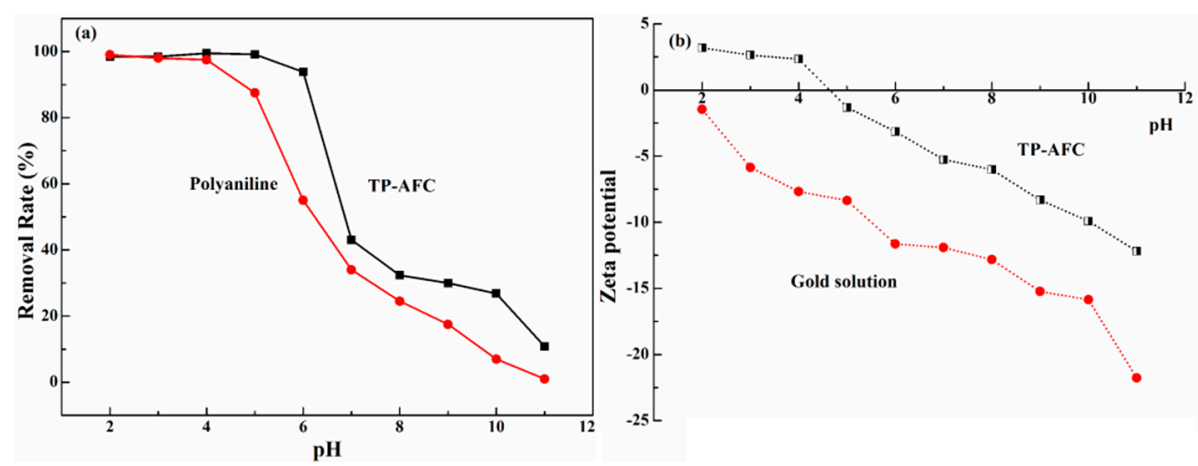

Figure 3. (a) Effect of $\mathrm{pH}$ on the $\mathrm{Au}(\mathrm{III})$ adsorption by polyaniline and TP-AFC and (b) zeta potential of TP-AFC and gold solution.

The net total surface charge of TP-AFC can be represented by the zero potential ( $\mathrm{pH}_{\mathrm{PZC}}$ ). The value of $\mathrm{pH}_{\mathrm{PZC}}$ charge can be determined by the method described in the literature [24]. The $\mathrm{pH}_{\mathrm{PZC}}$ of TP-AFC was 2.8. In order to study the adsorption mechanism, the zeta potential of TP-AFC and gold solution were also determined. As shown in Figure 3b, the isoelectric point of TP-AFC was 4.6, indicating that the potential was positive when $\mathrm{pH}$ was below 4.6. The gold solution showed a negative charge in the range of $\mathrm{pH} 2$ to $\mathrm{pH}$ 4. Hence, there has an electrostatic effect between TP-AFC and gold.

\subsection{Effect of Reaction Time}

The effect of the reaction time on adsorption capacity was studied in order to explore the adsorption mechanism. $10 \mathrm{mg}$ TP-AFC was added to $20 \mathrm{~mL}$ gold solutions ( $\mathrm{pH} 4$ ) and oscillated at $298 \mathrm{~K}$ with $250 \mathrm{rpm}$. The time was changed from 10 to $1440 \mathrm{~min}$. As can be seen from Figure $4 \mathrm{a}$, the removal rate increased from $14 \%$ to $95 \%$ as time increased from 10 to $840 \mathrm{~min}$, because many adsorption sites can rapidly combine with gold ions during the adsorption stage. As time goes by, the adsorption sites are few. Therefore, the removal rate did not change significantly after $840 \mathrm{~min}$. Therefore, $840 \mathrm{~min}$ is the optimal reaction time.

The adsorption kinetics was studied by pseudo-first-order kinetic model, pseudo-second-order kinetic model, and intraparticle kinetic model. The pseudo-first-order kinetic model assumes that the adsorption rate varies with the number of non-adsorbed sites on the surface of the adsorbent. Equation (3) is used to describe the relationship between them [25]:

$$
\ln \left(q_{b}-q_{t}\right)=\ln q_{b}-k_{1} t
$$

where $q_{b}$ and $q_{t}$ are the adsorption capacities at equilibrium time and at time $t$, respectively. $k_{1}$ is the rate constant of the Pseudo-first-order kinetic model. It can be seen from Figure $4 \mathrm{~b}$ and Table 1 that the value of the correlation coefficient is lower, and the theoretical equilibrium adsorption capacity $(292.5 \mathrm{mg} / \mathrm{g}$ ) is much lower than the actual equilibrium adsorption capacity $(399.6 \mathrm{mg} / \mathrm{g})$. Therefore, the adsorption process does not conform to the pseudo-first-order kinetic model. 

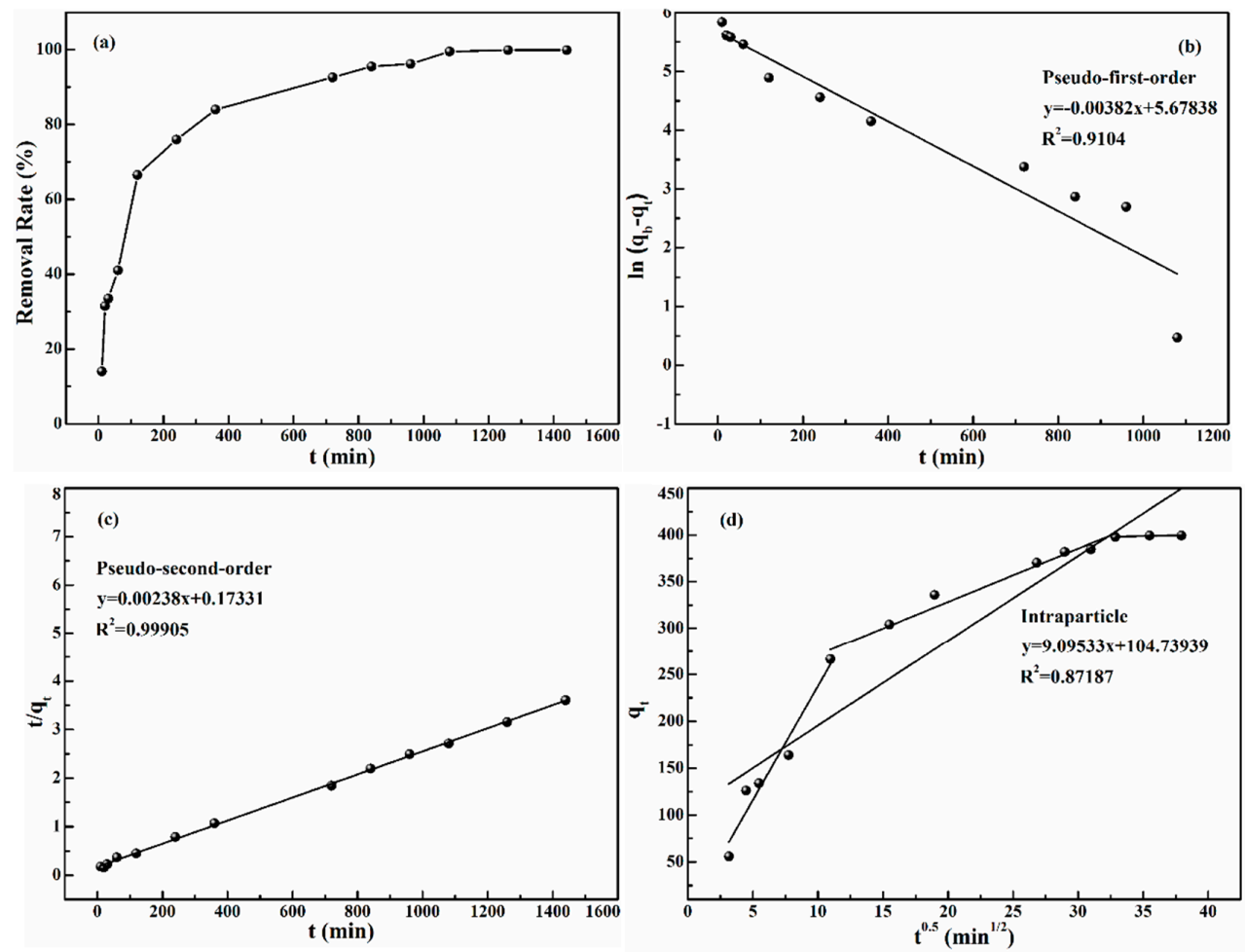

Figure 4. (a) Effect of the reaction time; (b) Pseudo-first-order model; (c) Pseudo-second-order model; (d) Intraparticle diffusion model.

Table 1. The parameters of the pseudo-first-order and pseudo-second-order kinetic models.

\begin{tabular}{ccc}
\hline Kinetic Models & Parameters & Values \\
\hline Pseudo-first-order & $q_{b}(\mathrm{mg} / \mathrm{g})$ & 292.48 \\
& $k_{1}$ & 0.0038 \\
& $R^{2}$ & 0.910 \\
& $\Delta q$ & 107.13 \\
Pseudo-second-order & $q_{b}(\mathrm{mg} / \mathrm{g})$ & 420.17 \\
& $k_{2}$ & 0.00003 \\
& $R^{2}$ & 0.999 \\
& $\Delta q$ & 20.57 \\
\hline
\end{tabular}

The pseudo-second-order kinetic model is based on chemisorption and is affected by the mass balance equation and the second-order rate derivative. Equation (4) is used to describe the pseudo-second-order kinetic model [26]:

$$
\frac{t}{q_{t}}=\frac{1}{k_{2} q_{b}^{2}}+\frac{t}{q_{b}}
$$

where $k_{2}$ is the rate constant of the pseudo-second-order kinetic model. It can be seen from Figure $4 \mathrm{c}$ and Table 1 that the correlation coefficient of the pseudo-second-order kinetic model (0.999) is much closer to 1 than that of the pseudo-first-order kinetic model (0.910). In addition, the theoretical equilibrium adsorption capacity $(420 \mathrm{mg} / \mathrm{g}$ ) calculated by the pseudo-second-order kinetic model is close to the actual equilibrium adsorption capacity $(399.6 \mathrm{mg} / \mathrm{g})$ and the $\Delta$ q value of the pseudo-second-order kinetic model is smaller than that of the pseudo-first-order kinetic model. Therefore, the pseudo-second-order kinetic model described the adsorption process and the whole process was chemsorption. 
The intraparticle diffusion model can further explain the adsorption process. Equation (5) is used to describe the intraparticle diffusion model [27]:

$$
q_{b}=k_{3} t^{1 / 2}+C
$$

where $k_{3}$ and $\mathrm{C}$ are the constants of the rate and the intraparticle diffusion model, respectively. As can be seen from Figure $4 \mathrm{~d}$ and Table 2, the intraparticle diffusion model is a complex linear relationship that can be divided into three stages. The first stage was a rapid adsorption process. This stage was mainly the diffusion of gold ions from the solution to the surface of the adsorbent. The second stage was a slow adsorption process. Gold ions diffused from the surface of the adsorbent to the interior of the adsorbent. At the last stage, there was no significant change in the amount of adsorption. At this stage, the gold ions diffused slowly and the adsorption sites had reached saturation.

Table 2. The parameters of three stages in intraparticle diffusion model.

\begin{tabular}{cccc}
\hline Parameters & Stage I & Stage II & Stage III \\
\hline$C$ & -6.42 & 214.28 & 387.79 \\
$k_{3}$ & 24.32 & 5.704 & 0.318 \\
$R^{2}$ & 0.933 & 0.97 & 0.535 \\
\hline
\end{tabular}

\subsection{Effect of Initial Concentration}

Isothermal adsorption experiments are very important to study the adsorption mechanism. $10 \mathrm{mg}$ TP-AFC was added to $20 \mathrm{~mL}$ gold solution with different concentrations $(285 \mathrm{mg} / \mathrm{L}, 380 \mathrm{mg} / \mathrm{L}, 475 \mathrm{mg} / \mathrm{L}$, $570 \mathrm{mg} / \mathrm{L} 665 \mathrm{mg} / \mathrm{L}$ and $760 \mathrm{mg} / \mathrm{L}$ ), respectively. It can be seen from Figure $5 \mathrm{a}$, the adsorption capacity of gold ions increased with the increasing of initial concentration. A high concentration of gold solution contributed to the binding of the adsorption site to the gold ions. The maximal adsorption capacity of TP-AFC for gold ions is $881 \mathrm{mg} / \mathrm{g}$. The adsorption test of polyaniline was also carried out under the same conditions. Figure $5 \mathrm{a}$ also shows that the maximal adsorption capacity of polyaniline for gold ions is $599 \mathrm{mg} / \mathrm{g}$, which is lower than that of TP-AFC.
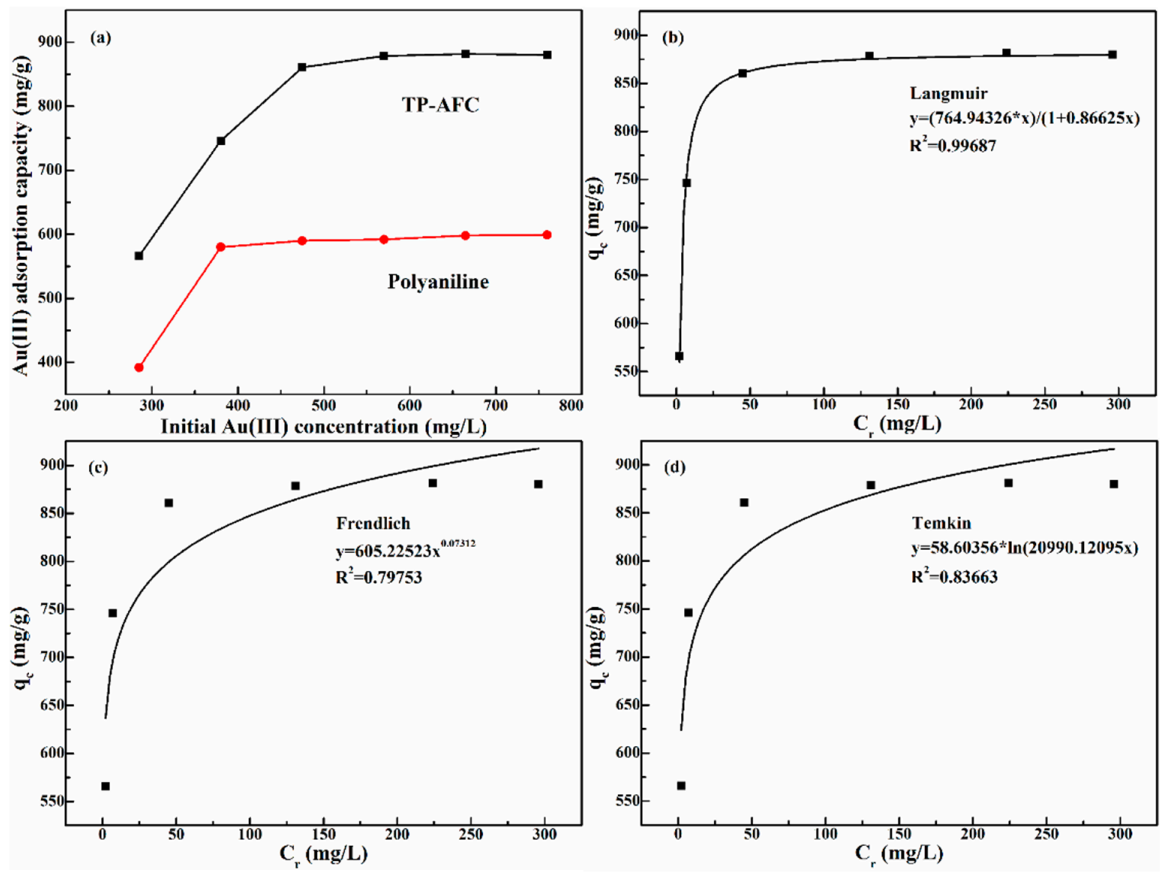

Figure 5. (a) the $\mathrm{Au}(\mathrm{III})$ concentration effect on adsorption capacity, isothermal adsorption model of gold on TP-AFC (b) Langmuir (c) Freundlich and (d) Temkin. 
In order to further study the adsorbing mechanism, three isothermal models were used to describe the adsorption process, including Langmuir, Freundlich and Temkin. Langmuir model describes single layer adsorption with no lateral effects or spatial barriers. Langmuir model can be expressed by Equation (6) [28]:

$$
q_{c}=\frac{q_{m} \cdot K_{L} \cdot C_{r}}{1+K_{L} \cdot C_{r}}
$$

where $q_{c}$ and $C_{r}$ represent the equilibrium adsorption capacity and the remaining concentration, respectively. $K_{L}$ is the constant of Langmuir model and $q_{m}$ is the maximum theoretical adsorption capacity.

The Freundlich model describes that the adsorption process occurs on a heterogeneous surface. The Freundlich model can be expressed by Equation (7) [29]:

$$
q_{c}=K_{F} \cdot C_{r}^{\frac{1}{n_{1}}}
$$

where $K_{F}$ represents the Freundlich constant and $n_{1}$ is the adsorption capacity index.

The Temkin model describes that the adsorption heat continually decreases as the adsorbent and adsorbate interact in different adsorbent layers. This model is based on chemisorptions. It can be expressed by Equation (8) [30]:

$$
q_{c}=\frac{R T \ln \left(K_{T} C_{r}\right)}{\beta}
$$

where $K_{T}$ and $\beta$ is the constant of the Temkin model. $\mathrm{R}$ and T are the constant of universal gas and temperature in Kelvin, respectively.

Figure $5 \mathrm{~b}-\mathrm{d}$ is the fitting curves of the three models. The relevant parameters of the models are listed in Table 3. The correlation constant $(1 / n)$ in the Freundlich model is in the range of 0 to 1 , indicating that adsorption is advantageous. The Temkin model isotherm provided additional information on the adsorbent-adsorbate binding interaction. The adsorption heat from the Temkin model indicated a strong interaction between the reactive group and the $\mathrm{Au}(\mathrm{III})$ ion. The correlation coefficient is $R^{2}{ }_{\mathrm{L}}>\mathrm{R}_{\mathrm{T}}{ }_{\mathrm{T}}>\mathrm{R}_{\mathrm{F}}^{2}$. At the same time, the theoretical maximum adsorption capacity was 883.05 $\mathrm{mg} / \mathrm{g}$, which is close to the actual adsorption capacity $(881 \mathrm{mg} / \mathrm{g}) . \Delta \mathrm{q}$ value of Langmuir $(2.01 \mathrm{mg} / \mathrm{g})$ is smaller than that of Freundlich $(275.77 \mathrm{mg} / \mathrm{g})$. Therefore, the Langmuir model well described the adsorption process.

Table 3. The parameters of different isotherms models.

\begin{tabular}{ccc}
\hline Isotherm Model Parameter & Parameter & Value \\
\hline Langmuir & $\mathrm{q}_{\mathrm{m}}(\mathrm{mg} / \mathrm{g})$ & 883.05 \\
& $\mathrm{~K}_{\mathrm{L}}(\mathrm{L} / \mathrm{g})$ & 0.866 \\
& $\mathrm{R}^{2}$ & 0.997 \\
& $\Delta \mathrm{q}$ & 2.01 \\
Freundlich & $\mathrm{K}_{\mathrm{F}}$ & 605.23 \\
& $\left(\mathrm{mg} \cdot \mathrm{g}^{-1}\left(\mathrm{~L} \cdot \mathrm{mg}^{-1}\right)^{1 / \mathrm{n}}\right)$ & 0.0731 \\
& $1 / \mathrm{n}$ & 0.798 \\
& $\mathrm{R}^{2}$ & 275.77 \\
Temkin & $\Delta \mathrm{q}$ & 38.73 \\
& $\beta$ & 20990.12 \\
& $\mathrm{~K}_{\mathrm{T}}(\mathrm{L} / \mathrm{g})$ & 0.837 \\
$\mathrm{R}^{2}$ & \\
\hline
\end{tabular}

The separation factor $\mathrm{K}_{\mathrm{s}}$ can be obtained from the Langmuir model. The $\mathrm{K}_{\mathrm{s}}$ value can be used to judge the superiority of the adsorption process. When $K_{s}=1$, the adsorption is reversible. When 
$0<\mathrm{K}_{\mathrm{s}}<1$, adsorption is advantageous and linear. When $\mathrm{K}_{\mathrm{s}}>1$, adsorption is disadvantageous. The value of $K_{s}$ can be expressed by Equation (9):

$$
K_{s}=\frac{1}{1+K_{L} \cdot C_{r}}
$$

Table 4 shows that the $\mathrm{K}_{\mathrm{s}}$ values of each $\mathrm{Au}(\mathrm{III})$ initial concentration were between 0.0015 to 0.004 , indicating that the adsorption process was favorable.

Table 4. The Langmuir-based $\mathrm{K}_{\mathrm{s}}$ value.

\begin{tabular}{cc}
\hline $\mathbf{C}_{\mathbf{i}}(\mathbf{m g} / \mathbf{L})$ & $\mathbf{K}_{\mathbf{s}}$ \\
\hline 285 & 0.004 \\
380 & 0.003 \\
475 & 0.0024 \\
570 & 0.002 \\
665 & 0.0017 \\
780 & 0.0015 \\
\hline
\end{tabular}

In order to study the difference between TP-AFC and other adsorbents, it was compared with various adsorbents, including adsorption capacity and $\mathrm{pH}$. As shown in Table 5, TP-AFC exhibits a higher adsorption capacity.

Table 5. Comparison of the adsorption capacity for gold ion.

\begin{tabular}{cccc}
\hline Adsorbents & $\mathbf{q}_{\mathbf{m a x}}(\mathbf{m g} / \mathbf{g})$ & $\mathbf{p H}$ & Litertures \\
\hline APS-LCP (lignocellulosic) & 261.36 & 4.0 & {$[31]$} \\
PS-APD resin (resin) & 278.5 & 4.0 & {$[32]$} \\
n-AMPRs (cellulose) & 537 & 2.0 & {$[33]$} \\
D301-g-THIOPGMA (resin) & 326 & 2.0 & {$[34]$} \\
BHJC (buckwheat hulls) & 425.5 & 2.5 & {$[35]$} \\
TP-AFC (polyaniline- trimethyl phosphate) & 881 & 4 & This work \\
\hline
\end{tabular}

\subsection{Thermodynamic Experiment}

The effect of temperature ( $293 \mathrm{~K}, 298 \mathrm{~K}$ and $303 \mathrm{~K}$ ) on the adsorption capacity was investigated under $\mathrm{pH} 4$ conditions. The increase of temperature has a positive effect on the adsorption of $\mathrm{Au}(\mathrm{III})$ by TP-AFC. Gibbs free energy $\left(\Delta G_{T}\right)$, enthalpy $\left(\Delta H_{T}\right)$, and entropy $\left(\Delta S_{T}\right)$ can be obtained from Equations (10) and (11):

$$
\begin{gathered}
\ln K_{Q}=\ln \frac{q_{c}}{C_{r}}=\frac{\Delta S_{T}}{R}-\frac{\Delta H_{T}}{R T} \\
\Delta G_{T}=-R T \ln \frac{q_{c}}{C_{r}}
\end{gathered}
$$

As shown in Figure 6 and Table 6 , the value of $\Delta H_{T}$ and $\Delta S_{T}$ were positive, indicating that the adsorption is an endothermic process. The value of $\Delta G_{T}$ was negative, indicating that the adsorption

\begin{tabular}{|c|c|c|c|c|}
\hline$\Delta \mathbf{H}_{\mathrm{T}}\left(\mathrm{J} \cdot \mathrm{mol}^{-1} \cdot \mathrm{K}^{-1}\right)$ & $\Delta \mathrm{S}_{\mathrm{T}}\left(\mathrm{J} \cdot \mathrm{mol}^{-1}\right)$ & $\mathbf{T}(\mathrm{K})$ & $\Delta \mathrm{G}_{\mathrm{T}}\left(\mathrm{J} \cdot \mathrm{mol}^{-1}\right)$ & $\mathbf{R}^{2}$ \\
\hline \multirow[t]{3}{*}{8591.21} & 34.51 & 293 & -1522.99 & 0.999971 \\
\hline & & 298 & -1679.05 & \\
\hline & & 303 & -1866.38 & \\
\hline
\end{tabular}
is spontaneous.

Table 6. Related thermodynamic parameters of gold adsorption. 


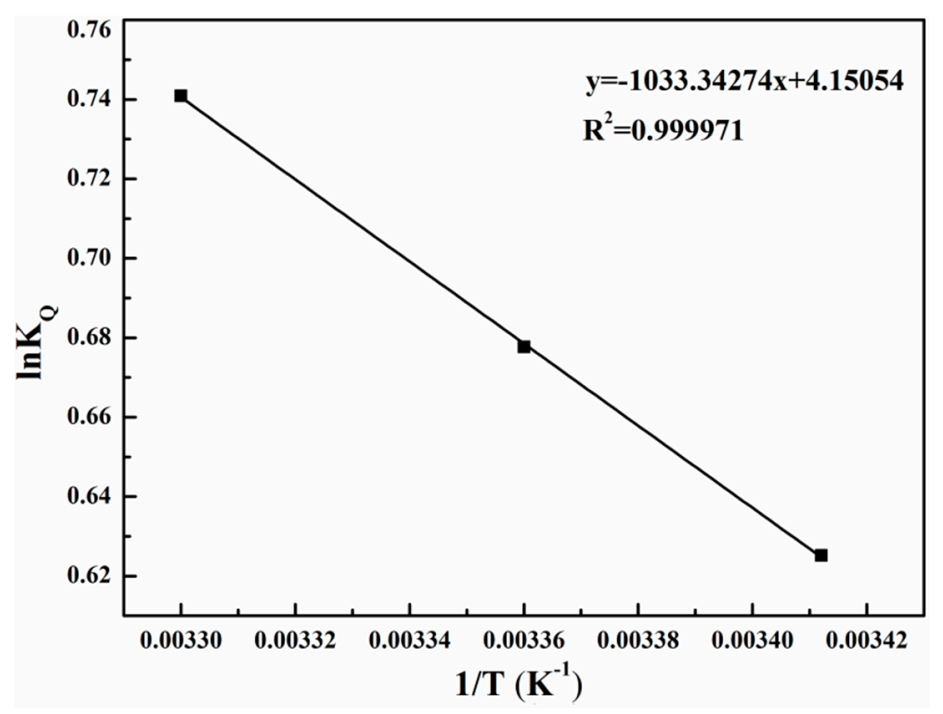

Figure 6. Effect of temperature on gold adsorption.

\subsection{Reusability and Desorption Studies of TP-AFC}

Recyclability of materials is important for their potential applications in field of water purification. In order to investigate the regenerative capacity of TP-AFC, a repetitive experiment was conducted. $30 \mathrm{mg}$ TP-AFC was added to $60 \mathrm{~mL}$ gold ions $(475 \mathrm{mg} / \mathrm{L})$ solution. And it was shaken at $250 \mathrm{rpm}$ for $24 \mathrm{~h}$ at room temperature $(298 \mathrm{~K})$. The concentration of the remaining solution was measured using ICP-OES after centrifugation. The precipitate was desorbed with $10 \%$ thiourea ( $2 \%$ hydrochloric acid) for $24 \mathrm{~h}$ and then the precipitate was washed with pure water for 5 times. Such experiment was performed three times. As shown in Table 7, the adsorption capacity decreased from $860 \mathrm{mg} / \mathrm{g}$ to $501.6 \mathrm{mg} / \mathrm{g}$ after three times, indicating that TP-AFC can still maintain a large adsorption capacity for gold after three cycles.

Table 7. The regeneration property of TP-AFC.

\begin{tabular}{cccc}
\hline Cycles & $\mathbf{1}$ & $\mathbf{2}$ & $\mathbf{3}$ \\
\hline Adsorption capacity (mg/g) & 860 & 620 & 501.6 \\
Removal rate (\%) & 90.5 & 65.3 & 52.8 \\
\hline
\end{tabular}

\subsection{Application of TP-AFC in Practical Wastewater}

The separation capacity of the adsorbent was tested by laboratory wastewater. The wastewater was firstly adjusted to $\mathrm{pH} 4$ and ICP-OES was used to measure the metal ion concentration in wastewater. Then, $10 \mathrm{mg}$ TP-AFC was added to $20 \mathrm{ml}$ wastewater and oscillated for $24 \mathrm{~h}$, respectively. After centrifugation, the residual concentration of the solution was measured (Figure 7). It can be seen that TP-AFC has higher selectivity for gold ions against the interference of various metal ions. The separation capacity of polyaniline was also tested according to the same procedure. However, polyaniline adsorbed not only gold ion but also cadmium and arsenic ions. Table 8 showed the related parameters of each metal ion on TP-AFC. The distribution coefficient $\left(\mathrm{K}_{\mathrm{Q}}\right)$ and selectivity coefficient (K) can be expressed by Equations (10) and (11). The experiment results showed that TP-AFC has a good prospect in practical application.

$$
\begin{gathered}
K_{Q}=\frac{Q}{C_{r}}=\frac{C_{i}-C_{r}}{C_{r}} \cdot \frac{V}{m} \\
K=\frac{K_{Q\left(A u^{3+}\right)}}{K_{Q(\text { coexisting ions })}}
\end{gathered}
$$




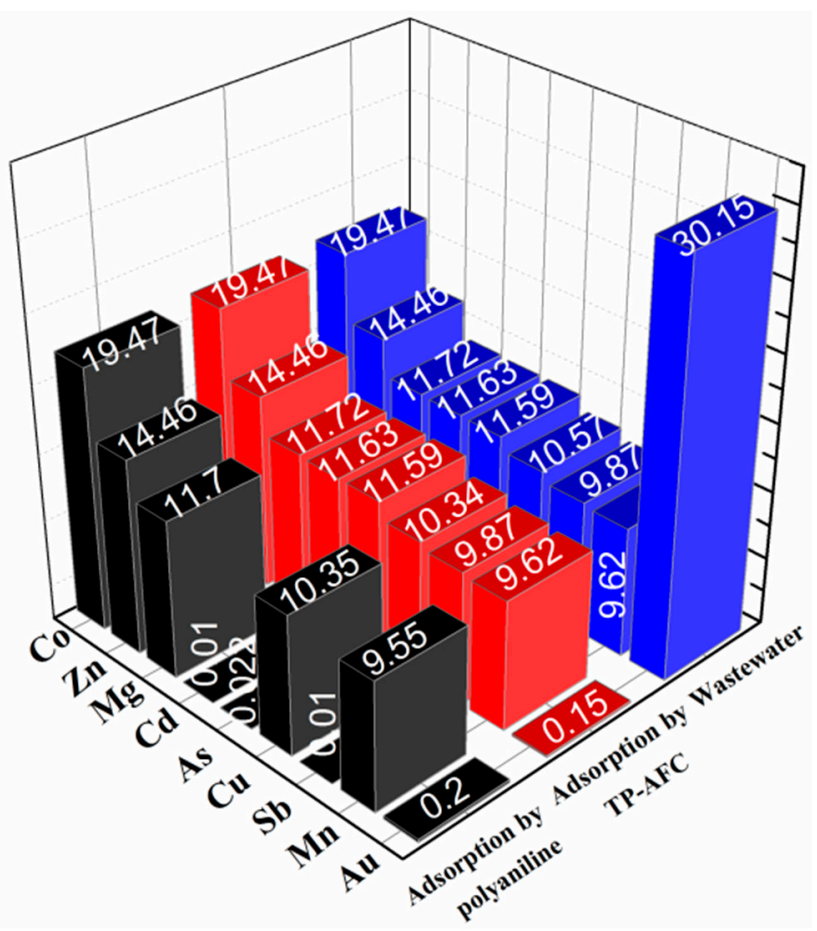

Figure 7. Effect of gold adsorption in wastewater.

Table 8. $\mathrm{K}_{\mathrm{Q}}$ and $\mathrm{K}$ of the ions in wastewater.

\begin{tabular}{ccc}
\hline Metal Ions & $\mathbf{K}_{\mathbf{Q}}(\mathbf{m L} / \mathbf{g})$ & $\mathbf{K}$ \\
\hline $\mathrm{Au}^{3+}$ & 400000 & - \\
$\mathrm{Mg}^{2+}$ & 0 & + \\
$\mathrm{Mn}^{2+}$ & 0 & + \\
$\mathrm{Co}^{2+}$ & 0 & + \\
$\mathrm{Cu}^{2+}$ & 44.49 & 8990.78 \\
$\mathrm{Zn}^{2+}$ & 0 & + \\
$\mathrm{As}^{3+}$ & 0 & + \\
$\mathrm{Sb}^{3+}$ & 0 & + \\
$\mathrm{Cd}^{2+}$ & 0 & + \\
\hline
\end{tabular}

\subsection{Adsorption Mechanism}

The excellent absorption capacity of TP-AFC for gold ion is mainly attributed to the strong interaction between phosphorus-containing functional groups and gold ions. In order to understand the mechanism of gold adsorption by TP-AFC, TP-AFC was characterized by XPS and SEM before and after adsorption. As shown in Figure 8a, the peak of Au4f appeared after adsorption, indicating that gold was absorbed by TP-AFC. As shown in Figure 8b, XPS of gold showed two peaks at 84.1 and $87.59 \mathrm{eV}$. In addition, XPS of $\mathrm{P}$ can be divided into two peaks at 132.78 and $133.71 \mathrm{eV}$ before adsorption (Figure 8c). The peaks shifted to 131.3 and $133.77 \mathrm{eV}$ after adsorption (Figure 8d), indicating that $\mathrm{P}$ played an important role in the adsorption process. SEM images of TP-AFC before and after adsorption are shown in Figure 9. It can be clearly seen that the gold is distributed throughout on the adsorbent after adsorption, but the morphology of the adsorbent does not change. In summary, combined with Zeta potential, XPS and SEM, the main mechanism of TP-AFC adsorption of gold is ion exchange and chelation. 

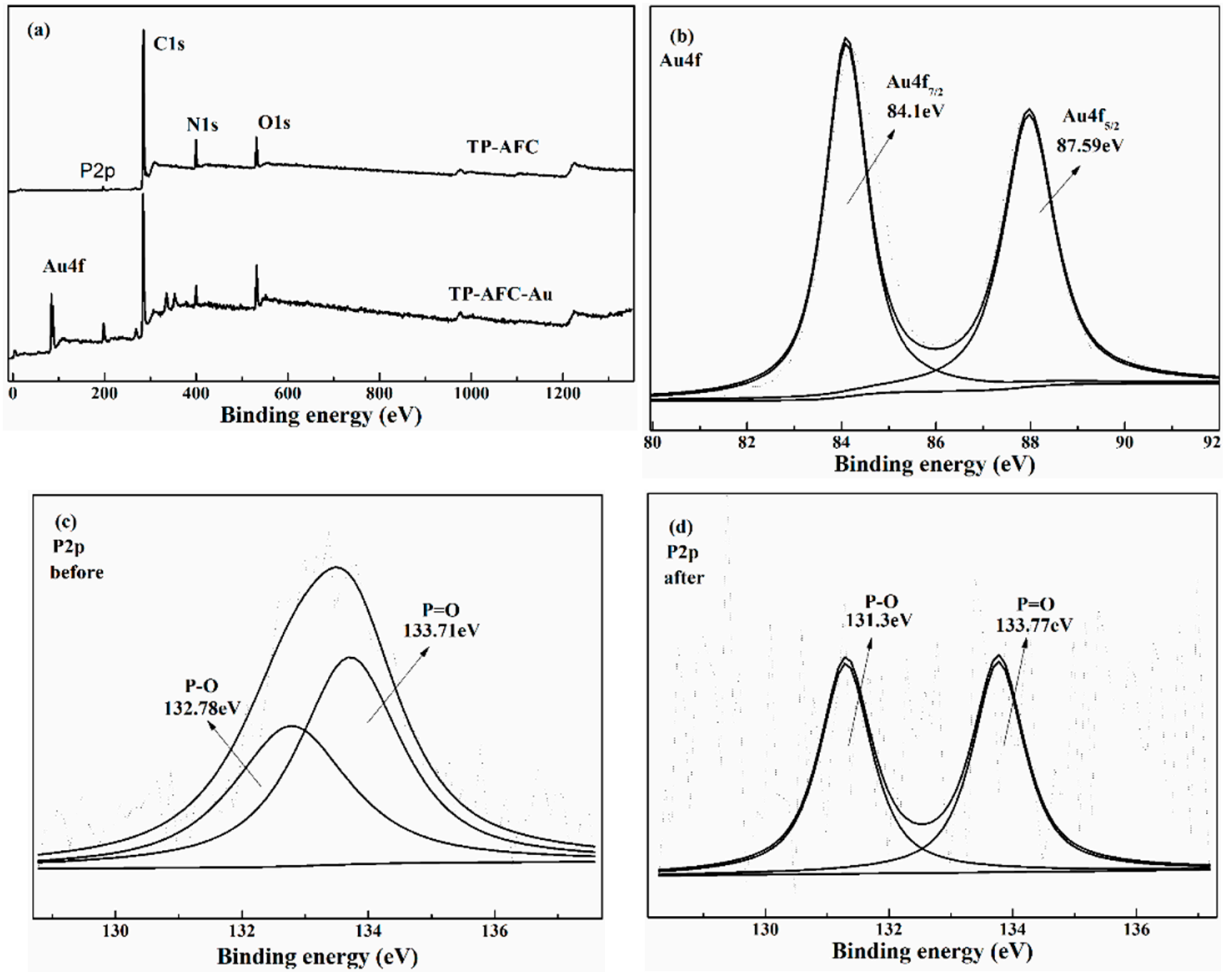

Figure 8. XPS spectra of TP-AFC before and after adsorption.

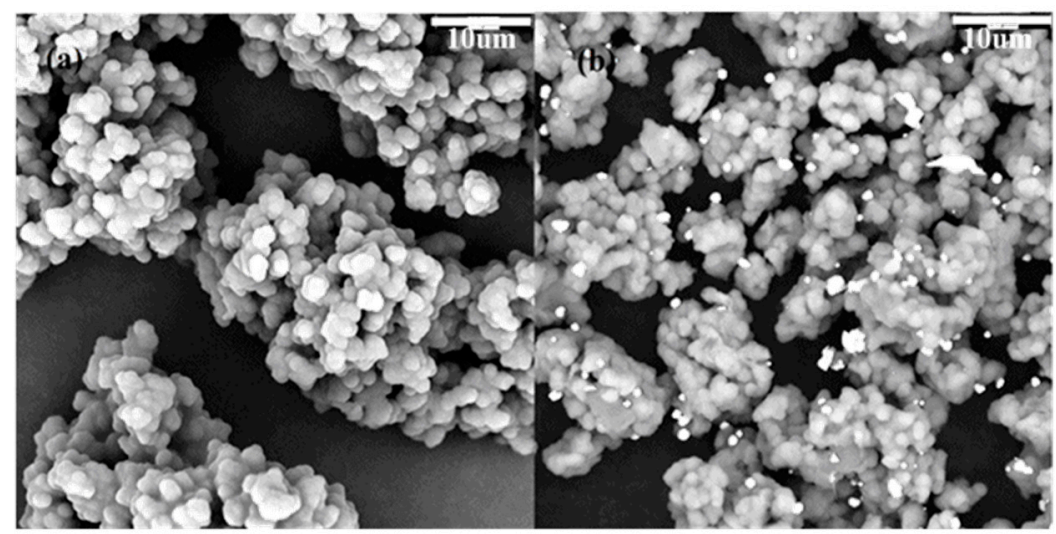

Figure 9. SEM images of TP-AFC before (a) and after (b) adsorption.

\section{Conclusions}

A polyaniline-based adsorbent was successfully prepared for the recovery of gold ions from wastewater. FT-IR, SEM, Zeta potential, and XPS were used to characterize TP-AFC, which has a good adsorption capacity at $\mathrm{pH} 4$. The Langmuir model and pseudo second-order kinetic model describe the adsorption process well. The process is controlled by a single layer chemisorption. Thermodynamic experiments indicated that the adsorption is a spontaneous endothermic process. The adsorption mechanism is mainly the chelation and ion exchange of $\mathrm{Au}(\mathrm{III})$ with phosphorus. In the actual wastewater experiment, the coexisting ions have little interference on the recovery of gold. In general, TP-AFC has a good prospect in recycling gold from wastewater.

Author Contributions: S.W. and L.Z. conceived and designed the experiments; C.W., J.Z. performed the experiments and wrote the paper; J.Z. and B.Z. analyzed the data.

Funding: The support from the National Natural Science Foundation (U1702252). 
Acknowledgments: In this section you can acknowledge any support given which is not covered by the author contribution or funding sections. This may include administrative and technical support, or donations in kind (e.g., materials used for experiments).

Conflicts of Interest: The authors declare no conflict of interest.

\section{References}

1. Agarwal, C.; Cattrall, R.W.; Kolev, S.D. Donnan dialysis based separation of gold(III) from electronic waste solutions using an anion exchange pore-filled membrane. J. Membr. Sci. 2016, 514, 210-216. [CrossRef]

2. Parajuli, D.; Adhikari, C.R.; Kawakita, H.; Kajiyama, K.; Ohto, K.; Inoue, K. Reduction and accumulation of $\mathrm{Au}(\mathrm{III})$ by grape waste: A kinetic approach. React. Funct. Polym. 2008, 68, 1194-1199. [CrossRef]

3. Liu, L.; Li, C.; Bao, C.; Jia, Q.; Xiao, P.; Liu, X.; Zhang, Q. Preparation and characterization of chitosan/graphene oxide composites for the adsorption of $\mathrm{Au}(\mathrm{III})$ and $\mathrm{Pd}(\mathrm{II})$. Talanta 2012, 93, 350-357. [CrossRef] [PubMed]

4. Zhao, P.; Li, N.; Astruc, D. State of the art in gold nanoparticle synthesis. Coord. Chem. Rev. 2013, 257, 638-665. [CrossRef]

5. Du, M.; Zhan, G.; Yang, X.; Wang, H.; Lin, W.; Zhou, Y.; Zhu, J.; Lin, L.; Huang, J.; Sun, D.; et al. Ionic liquid-enhanced immobilization of biosynthesized Au nanoparticles on TS-1 toward efficient catalysts for propylene epoxidation. J. Catal. 2011, 283, 192-201. [CrossRef]

6. Soylak, M.; Saracoglu, S.; Divrikli, U.; Elci, L. Coprecipitation of heavy metals with erbium hydroxide for their flame atomic absorption spectrometric determinations in environmental samples. Talanta 2005, 66, 1098-1102. [CrossRef]

7. Nayak, D.; Banerjee, A.; Lahiri, S. Separation of no-carrier-added 66, 67 Ga produced in heavy ion-induced cobalt target using alginate biopolymers. Appl. Radiat. Isot. 2007, 65, 891-896. [CrossRef]

8. Lin, G.; Wang, S.; Zhang, L.; Hu, T.; Peng, J.; Cheng, S.; Fu, L.; Xiong, C. Enhanced and selective adsorption of $\mathrm{Hg}^{2+}$ to a trace level using trithiocyanuric acid-functionalized corn bract. Environ. Pollut. 2019, 244, 938-946. [CrossRef] [PubMed]

9. Alguacil, F.J.; Adeva, P.; Alonso, M. Processing of residual gold (III) solutions via ion exchange. Gold Bull. 2005, 38, 9-13. [CrossRef]

10. Lin, G.; Hu, T.; Wang, S.; Xie, T.; Zhang, L.; Cheng, S.; Fu, L.; Xiong, C. Selective removal behavior and mechanism of trace $\mathrm{Hg}$ (II) using modified corn husk leaves. Chemosphere 2019, 225, 65-72. [CrossRef]

11. Yin, Z.; Wang, Y.; San, J. Adsorption behavior of hydroxypropyl guar gum onto montmorillonite and reducing adsorption in the reservoir. Appl. Clay Sci. 2018, 166, 123-130. [CrossRef]

12. Zhou, X.; Yang, Y.; Li, C.; Yang, Z.; Yang, W.; Tian, Z.; Zhang, L.; Tao, T. Environmental-friendly one-step fabrication of tertiary amine-functionalized adsorption resins for removal of benzophenone-4 from water. J. Clean. Prod. 2018, 203, 655-663. [CrossRef]

13. Kraus, M.; Trommler, U.; Holzer, F.; Kopinke, F.-D.; Roland, U. Competing adsorption of toluene and water on various zeolites. Chem. Eng. J. 2018, 351, 356-363. [CrossRef]

14. Siyal, A.A.; Shamsuddin, M.R.; Khan, M.I.; Rabat, N.E.; Zulfiqar, M.; Man, Z.; Siame, J.; Azizli, K.A. A review on geopolymers as emerging materials for the adsorption of heavy metals and dyes. J. Environ. Manag. 2018, 224, 327-339. [CrossRef] [PubMed]

15. Rahmati, M.; Mozafari, M. Protein adsorption on polymers. Mater. Today Commun. 2018, 17, 527-540. [CrossRef]

16. Yarandpour, M.R.; Rashidi, A.; khajavi, R.; Eslahi, N.; Yazdanshenas, M.E. Mesoporous PAA/dextranpolyaniline core-shell nanofibers: Optimization of producing conditions, characterization and heavy metal adsorptions. J. Taiwan Inst. Chem. E 2018, 93, 566-581. [CrossRef]

17. Shen, J.; Shahid, S.; Amura, I.; Sarihan, A.; Tian, M.; Emanuelsson, E.A.C. Enhanced adsorption of cationic and anionic dyes from aqueous solutions by polyacid doped polyaniline. Synth. Met. 2018, 245, 151-159. [CrossRef]

18. Osaka, Y.; Kotani, S.; Tsujiguchi, T.; Kodama, A.; Huang, H. Experimental investigation on the adsorption kinetics of silica-gel layer enhanced thermal conductivity. Appl. Therm. Eng. 2019, 148, 324-330. [CrossRef]

19. Zhao, X.; Zeng, X.; Qin, Y.; Li, X.; Zhu, T.; Tang, X. An experimental and theoretical study of the adsorption removal of toluene and chlorobenzene on coconut shell derived carbon. Chemosphere 2018, 206, 285-292. [CrossRef] [PubMed] 
20. Du, Z.; Zheng, T.; Wang, P. Experimental and modelling studies on fixed bed adsorption for Cu(II) removal from aqueous solution by carboxyl modified jute fiber. Powder Technol. 2018, 338, 952-959. [CrossRef]

21. Liu, H.; Dai, P.; Zhang, J.; Zhang, C.; Bao, N.; Cheng, C.; Ren, L. Preparation and evaluation of activated carbons from lotus stalk with trimethyl phosphate and tributyl phosphate activation for lead removal. Chem. Eng. J. 2013, 228, 425-434. [CrossRef]

22. Terangpi, P.; Chakraborty, S.; Ray, M. Improved removal of hexavalent chromium from $10 \mathrm{mg} / \mathrm{L}$ solution by new micron sized polymer clusters of aniline formaldehyde condensate. Chem. Eng. J. 2018, 350, 599-607. [CrossRef]

23. Nagireddi, S.; Golder, A.K.; Uppaluri, R. Investigation on Pd (II) removal and recovery characteristics of chitosan from electroless plating solutions. J. Water Process. Eng. 2017, 19, 8-17. [CrossRef]

24. Yao, S.; Zhang, D.; Shen, R.; Gu, X.; Zhao, M.; Liang, J. Removal of Pb(II) from water by the activated carbon modified by nitric acid under microwave heating. J. Colloids Intersace Sci. 2016, 463, 118-127. [CrossRef]

25. Huang, Y.-D. Comments on using of "pseudo-first-order model" [Appl. Surf. Sci. 394 (2017) 378-385, 397 (2017) 133-143, 426 (2017) 545-553, 437 (2018) 294-303]. Appl. Surf. Sci. 2019, 469, 564-565. [CrossRef]

26. Moussout, H.; Ahlafi, H.; Aazza, M.; Maghat, H. Critical of linear and nonlinear equations of pseudo-first order and pseudo-second order kinetic models. Karbala Int. J. Mod. Sci. 2018, 4, 244-254. [CrossRef]

27. Liu, C.; Cao, J. Potential role of intraparticle diffusion in dynamic partitioning of secondary organic aerosols. Atmos. Pollut. Res. 2018, 9, 1131-1136. [CrossRef]

28. Azizian, S.; Eris, S.; Wilson, L.D. Re-evaluation of the century-old Langmuir isotherm for modeling adsorption phenomena in solution. Chem. Phys. 2018, 513, 99-104. [CrossRef]

29. Sun, X.; Zhu, J.; Gu, Q.; You, Y. Surface-modified chitin by TEMPO-mediated oxidation and adsorption of Cd(II). Colloids Surf. A 2018, 555, 103-110. [CrossRef]

30. Araújo, C.S.T.; Almeida, I.L.S.; Rezende, H.C.; Marcionilio, S.M.L.O.; Léon, J.J.L.; Matos, T.N.D. Elucidation of mechanism involved in adsorption of $\mathrm{Pb}(\mathrm{II})$ onto lobeira fruit (Solanum lycocarpum) using Langmuir, Freundlich and Temkin isotherms. Microchem. J. 2018, 137, 348-354. [CrossRef]

31. Saman, N.; Rashid, M.U.; Lye, J.W.P.; Mat, H. Recovery of Au(III) from an aqueous solution by aminopropyltriethoxysilane-functionalized lignocellulosic based adsorbents. React. Funct. Polym. 2018, 123, 106-114. [CrossRef]

32. Changmei, S.; Guanghua, Z.; Chunhua, W.; Rongjun, Q.; Ying, Z.; Quanyun, G. A resin with high adsorption selectivity for Au (III): Preparation, characterization and adsorption properties. Chem. Eng. J. 2011, 172, 713-720. [CrossRef]

33. Dong, Z.; Liu, J.; Yuan, W.; Yi, Y.; Zhao, L. Recovery of Au(III) by radiation synthesized aminomethyl pyridine functionalized adsorbents based on cellulose. Chem. Eng. J. 2016, 283, 504-513. [CrossRef]

34. An, F.-Q.; Li, M.; Wu, R.-Y.; Hu, T.-P.; Gao, J.-F.; Yuan, Z.-G. Effective recovery of AuCl ${ }^{4-}$ using D301 resin functionalized with ethylenediamine and thiourea. Hydrometallurgy 2017, 169, 356-361. [CrossRef]

35. Deng, K.; Yin, P.; Liu, X.; Tang, Q.; Qu, R. Modeling, analysis and optimization of adsorption parameters of $\mathrm{Au}(\mathrm{III})$ using low-cost agricultural residuals buckwheat hulls. J. Ind. Eng. Chem. 2014, 20, 2428-2438. [CrossRef]

(C) 2019 by the authors. Licensee MDPI, Basel, Switzerland. This article is an open access article distributed under the terms and conditions of the Creative Commons Attribution (CC BY) license (http://creativecommons.org/licenses/by/4.0/). 